\title{
Plasmid-Mediated Resistance to Antibiotic Synergism in
}

\section{Enterococci}

\author{
Donald J. Krogstad, Thomas R. Korfhagen, Robert C. Moellering, Jr., \\ Christine Wennersten, and Morton N. Swartz, Departments of Medicine, \\ Harvard Medical School and Massachusetts General Hospital, Infectious Disease \\ Unit, Boston, Massachusetts 02114
}

\begin{abstract}
A B S T RACT Mating experiments have shown that high-level resistance (minimal inhibitory concentration $>2,000 \mu \mathrm{g} / \mathrm{ml}$ ) to streptomycin and kanamycin, and resistance to penicillin-streptomycin and penicillinkanamycin synergism are transferable by conjugation from resistant clinical isolates of enterococci to a sensitive recipient strain. Cesium chloride-ethidium bromide ultracentrifugation revealed a satellite (plasmid) band in resistant clinical isolates and the transconjugant strains but not in the sensitive recipient. Examination of these satellite bands by agarose gel electrophoresis and electron microscopy demonstrated a common plasmid with a weight of $\mathbf{4 5}$ megadaltons.

Novobiocin treatment of a resistant clinical isolate produced simultaneous loss of high-level resistance to streptomycin and kanamycin, and of resistance to penicillin-aminoglycoside synergism.
\end{abstract}

These results suggest that $(a)$ high-level resistance to streptomycin and kanamycin among some clinical isolates of enterococci is associated with a 45 megadalton plasmid, and $(b)$ the same plasmid is also responsible for the resistance to penicillin-aminoglycoside synergism observed in these strains.

\section{INTRODUCTION}

Enterococci are less susceptible to penicillin than other streptococci (minimal inhibitory concentration 4-8 vs. 0.03-0.12 U/ml) (1), and enterococcal infections have historically been more resistant to treatment with single antimicrobial agents than infections with other streptococci. However, since the reports of Hunter

Presented in part at the Interscience Conference on Antimicrobial Agents and Chemotherapy, October 1977, New York.

Address reprint requests to Dr. Moellering at the Infectious Disease Unit, Massachusetts General Hospital, Boston, Mass. 02114.

Received for publication 21 October 1977 and in revised form 30 January 1978. in 1947 (2), and Jawetz et al. in 1950 (3), it has been known that combinations of penicillin and an aminoglycoside synergize to produce enhanced killing of enterococci both in vitro (4) and in vivo (5), and are significantly more effective than penicillin alone. Previous studies from this laboratory have suggested that synergism results from enhanced uptake of aminoglycosides into enterococci in the presence of penicillin or other agents which inhibit bacterial cell wall synthesis (6).

Synergistic therapy resulting from the use of penicillin and an aminoglycoside is now the basis for treatment of serious human enterococcal infections. Therefore, we have been especially interested in the $25-50 \%$ of clinical isolates of enterococci with high-level resistance (minimal inhibitory concentration $>2,000 \mu \mathrm{g} / \mathrm{ml}$ ) to streptomycin and kanamycin which have now been reported from several cities, including Denver (7), Seattle (8), Boston (9), and London (10). The resistance observed in these strains is far above levels that are achievable in serum without producing unacceptable toxicity (20-25 $\mu \mathrm{g} / \mathrm{ml}$ for streptomycin and kanamycin). However, it is clinically relevant because strains with high-level aminoglycoside resistance are also resistant to antibiotic synergism with penicillin and that aminoglycoside (11). The origin and nature of high-level aminoglycoside resistance and resistance to antibiotic synergism among clinical isolates of enterococci are presently unknown.

We undertook the studies reported here to determine if the high-level aminoglycoside resistance observed among clinical isolates of enterococci was transferable, and if resistance to penicillin-aminoglycoside synergism was transferable simultaneously.

\section{METHODS}

\section{Strains, media, and antibiotics}

Resistant enterococci were selected as previously described (9) by screening enterococcal isolates from blood cultures of 
patients hospitalized at the Massachusetts General Hospital from 1968 to 1976 . Before use in mating experiments, the presence of high-level resistance was verified by growth on brain heart infusion (BHI) ${ }^{1}$ agar ( $1.5 \%$ agar) plates containing $2,000 \mu \mathrm{g} / \mathrm{ml}$ of aminoglycoside. Resistant strains grew on both streptomycin and kanamycin containing BHI plates. The sensitive recipient strain $\mathrm{JH} 2-7$ which required thymine (2 $\mu \mathrm{g} / \mathrm{ml}$ ) for growth in liquid media was kindly provided by Alan Jacob. This strain was resistant to fusidic acid and rifampin, but sensitive to aminoglycosides (minimal inhibitory concentration $<100 \mu \mathrm{g} / \mathrm{ml}$ for streptomycin and kanamycin) (12). All enterococcal strains used in these studies, including the resistant clinical isolates, the sensitive recipient JH2-7, and transconjugant JH2-7 (pDRl) were Streptococcus faecalis strains, and were speciated according to standard criteria (13).

We used BHI agar plates with either rifampin (100 $\mu \mathrm{g} / \mathrm{ml})$ or fusidic acid $(25 \mu \mathrm{g} / \mathrm{ml})$ to select for the recipient strain JH2-7; BHI agar with either streptomycin $(2,000$ $\mu \mathrm{g} / \mathrm{ml})$ or kanamycin $(2,000 \mu \mathrm{g} / \mathrm{ml})$ to select for the resistant clinical isolates; and combinations of rifampin and kanamycin $(100 \mu \mathrm{g} / \mathrm{ml}$ and $1,000 \mu \mathrm{g} / \mathrm{ml})$ or fusidic acid and streptomycin $(25 \mu \mathrm{g} / \mathrm{ml}$ and $1,000 \mu \mathrm{g} / \mathrm{ml})$ to select for transconjugants after mating experiments. Broth cultures utilized liquid BHI medium (except for novobiocin treatment which was carried out in Pen-Assay Broth, Difco Laboratories, Detroit, Mich.), and all incubations were at $37^{\circ} \mathrm{C}$. Thymine (Sigma Chemical Co., St. Louis, Mo.) solution, sterilized by passage through a $0.45-\mu \mathrm{m}$ Millipore filter (Millipore Corp., Bedford, Mass.), was added to liquid BHI medium for a final concentration of $2 \mu \mathrm{g} / \mathrm{ml}$. Antibiotic containing media were prepared by adding an appropriate amount of antibiotic solution after the BHI agar medium had been autoclaved and allowed to cool to $60^{\circ} \mathrm{C}$. Commercial preparations of injectable streptomycin (Eli Lilly \& Co., Indianapolis, Ind.) and kanamycin (Bristol Laboratories, Syracuse, N. Y.) were employed. Rifampin (Calbiochem, San Diego, Calif.) was dissolved in dimethylsulfoxide $(25 \mathrm{mg} / \mathrm{ml}$ ), diluted with distilled water (to $5 \mathrm{mg}$ / $\mathrm{ml}$ ), and sterilized by passage through a $0.45-\mu \mathrm{m}$ Millipore filter (Millipore Corp.) before use. Fusidic acid, kindly provided by Leo Pharmaceutical Products, Copenhagen, was dissolved in distilled water $(1.0 \mathrm{mg} / \mathrm{ml})$ and also sterilized by filtration.

\section{Reagents and enzymes}

For electron microscopy, cytochrome $c$ was obtained from Sigma Chemical Co., uranyl acetate from Fisher Scientific Co., Pittsburg, Pa., gold shield ethanol from IMC Chemical Group, Inc., Boston, Mass.; copper grids (200 mesh, 3HGC200), platinum-palladium wire (80:20, 0.008-inch diameter), tungsten wire $(0.020$-inch diameter) were obtained from Pelco, Ted Pella, Inc., Tustin, Calif., and parlodion $(3.5 \%$ Collodion Solution in amyl acetate) from Ladd Research Industries, Inc., Burlington, Vt. Lysozyme (Sigma Chemical Co.) solutions were prepared on the day of use and kept at $0^{\circ} \mathrm{C}$ until needed. Pronase (Calbiochem) was dissolved in Tris $(0.05 \mathrm{M}, \mathrm{pH} 8.0)$ at $20 \mathrm{mg} / \mathrm{ml}$ and self-digested for $2 \mathrm{~h}$ at $37^{\circ} \mathrm{C}$. RNase A, type IA (Sigma Chemical Co.,) was dissolved in ammonium acetate $(0.05 \mathrm{M}, \mathrm{pH} 5.0)$ at $1.0 \mathrm{mg} / \mathrm{ml}$, heated to $85^{\circ} \mathrm{C}$ for $15 \mathrm{~min}$ and cooled at room temperature. Deoxyribonuclease I (DNase I, Worthington

${ }^{1}$ Abbreviations used in this paper: $\mathrm{BHI}$, brain heart infusion; TES, $50 \mathrm{mM}$ Tris, $5 \mathrm{mM} \mathrm{Na} \mathrm{NaDTA}_{2}, 50 \mathrm{mM} \mathrm{NaCl}$, pH 8.0.
Biochemical Corp., Freehold, N. J.) was dissolved in sterile distilled water $(0.5 \mathrm{mg} / \mathrm{ml})$. After preparation, aliquots of pronase, RNase A, and DNase I were frozen in small vials at $-20^{\circ} \mathrm{C}$, then thawed rapidly in a $37^{\circ} \mathrm{C}$ water bath when needed and used only once.

\section{Mating experiments}

Single colonies of donor and recipient strains were inoculated into liquid $\mathrm{BHI}$, and grown overnight. The following morning, $0.2 \mathrm{ml}$ of overnight culture was inoculated into $20 \mathrm{ml}$ of fresh liquid BHI and the cells were grown, with shaking, to mid-log phase. For mating 0.1-ml samples of donor and recipient cultures were added to $9.8 \mathrm{ml}$ of liquid BHI. They were then incubated for $24 \mathrm{~h}$ with slow shaking. Control flasks for each experiment included donor and recipient cultures alone, and uninoculated $\mathrm{BHI}$.

Presumed transconjugant strains from doubly selective media (either rifampin and kanamycin or fusidic acid and streptomycin) were plated again for single colonies on the same media, and then tested for all four resistance markers using a modified Steers replicator (14). Only colonies bearing all four resistance markers were considered to be transconjugants.

\section{Mating experiment controls for transformation and transduction}

Transformation. Donor and recipient cultures were grown to log phase and mixed for mating in the presence of DNase I $(10 \mu \mathrm{g} / \mathrm{ml})$ and $\mathrm{MgSO}_{4}(5 \mathrm{mM})$ (12). These mating mixtures and controls were incubated for only $4 \mathrm{~h}$.

Additional studies included the use of $\left[{ }^{3} \mathrm{H}\right] \mathrm{DNA}$, kindly provided by Charles Richardson, to assess the activity of DNase I throughout a 4-h mating. After adding DNase I (final concentration $10 \mu \mathrm{g} / \mathrm{ml}$ ) at zero time, $\left[{ }^{3} \mathrm{H}\right] \mathrm{DNA}$ was added at 1 and $3 \mathrm{~h}$. Aliquots $(60 \mu \mathrm{l})$ of the mating mixture were added to carrier DNA $(60 \mu \mathrm{l}$ of $1.2 \mathrm{mM}$ DNA $[1.2 \mu \mathrm{mol}$ of DNA nucleotide $/ \mathrm{ml})$ and water $(120 \mu \mathrm{l})$, followed by $10 \%$ TCA $(0.5 \mathrm{ml})$ and held at $0^{\circ} \mathrm{C}$ for $10 \mathrm{~min}$ (Carrier DNA was diluted to $1.2 \mathrm{mM}$ with the molar extinction coefficient, $6.9 \mathrm{mM}$ at $260 \mu \mathrm{m}$ ). After the addition of $3.0 \mathrm{ml}$ of chilled 1.0 N HCl, the mixture was pipetted onto prewetted (1.0 N HCl) glass fiber filter paper disks (Whatman $\mathrm{GF} / \mathrm{C}$, Whatman, Inc., Clifton, N. J., $\mathbf{W}$ and $\mathbf{R}$ Balston, Ltd., England), flushed twice with $3.0 \mathrm{ml}$ of chilled $\mathrm{HCl}$ and washed with $80 \mathrm{ml}$ of $\mathrm{HCl}$, before the addition of absolute ethanol $(5.0 \mathrm{ml})$. Disks were then dried and counted in Omnifluor (New England Nuclear, Boston, Mass.)/toluene. Controls included tubes without $\left[{ }^{3} \mathrm{H}\right] \mathrm{DNA}$ and without DNase 1. To evaluate the effect of DNase I on transfer of resistance, selective media were again employed to calculate the number of donor, recipient, and transconjugant organisms per milliliter, and thus the frequency of transfer.

\section{Transduction}

The supernate of a mid-log phase donor culture was filtered after centrifugation at $4,500 \mathrm{~g}$ for $15 \mathrm{~min}$ at $4^{\circ} \mathrm{C}$ and mixed with a mid-log phase culture of the recipient strain. In addition, donor cultures in mid-log phase were treated with chloroform $(0.2 \mathrm{ml}$ in $10 \mathrm{ml})$ and the filtrate, after shaking for $2 \mathrm{~h}$ at $37^{\circ} \mathrm{C}$ to remove the chloroform and after passage through a $0.45-\mu \mathrm{m}$ Millipore filter (Millipore Corp.) to remove viable bacteria, was mixed with a mid-log phase culture of the recipient strain (12). Evidence of bacteriophage plaque production was sought by placing several 
drops of donor cultures on plain BHI plates overlaid with soft agar $(0.8 \%)$ containing the recipient strain, JH2-7. The supernates of donor cultures were tested after centrifugation, after filtration, and after chloroform treatment (12).

\section{Cesium chloride-ethidium bromide ultracentrifugation}

Two methods were used. The first was that of Jacob and Hobbs (12) with several modifications. Late-log phase cells from $100 \mathrm{ml}$ of liquid $\mathrm{BHI}$ were harvested by centrifugation at $4500 \mathrm{~g}$ for $15 \mathrm{~min}$ at $4^{\circ} \mathrm{C}$. The cells were resuspended and washed twice in $5.0 \mathrm{ml}$ of $50 \mathrm{mM}$ Tris, 5 mM Na${ }_{2}$ EDTA, $50 \mathrm{mM} \mathrm{NaCl}$, pH 8.0 (TES). Final resuspension was in $1.25 \mathrm{ml}$ of TES/10\% sucrose (wt/vol). Then $1.25 \mathrm{ml}$ of TES/10\% sucrose containing $2 \mathrm{mg}$ of lysozyme and $1 \mathrm{mg}$ of RNase A (not heat inactivated) per $\mathrm{ml}$ was added and the mixture was incubated at $37^{\circ} \mathrm{C}$ for $2 \mathrm{~h}$. Lysis was accomplished by the addition of $1.25 \mathrm{ml}$ of $\mathrm{N}$-lauroylsarcosine (Sigma Chemical Co., 2.4\% wt/vol in distilled water). After the further addition of $2.5 \mathrm{ml}$ of TES, the lysate was sheared by drawing it in and out of a $5.0-\mathrm{ml}$ serological pipette 20 times. Individual gradient tubes contained $6.91 \mathrm{~g}$ of $\mathrm{CsCl}$ (optical quality, Calbiochem), $4.5 \mathrm{ml}$ of TES, $1.5 \mathrm{ml}$ of TES with $1.5 \mathrm{mg} / \mathrm{ml}$ of ethidium bromide (Calbiochem), and $1.725 \mathrm{ml}$ of sheared lysate. After mixing, the refractive index of gradients varied from 1.386 to 1.387 .

The second method employed for preparation of cesium chloride-ethidium bromide gradients was a modification of the procedure of Palchaudhuri and Chakrabarty (15). A $500-\mathrm{ml}$ culture in liquid BHI was grown to late-log phase and harvested as described above. Cells were resuspended in $12.5 \mathrm{ml}$ of Tris $(0.05 \mathrm{M}, \mathrm{pH} 8.0) / 25 \%$ sucrose (wt/wt) and frozen overnight. The following morning, they were thawed rapidly in a $37^{\circ} \mathrm{C}$ water bath and $1.25 \mathrm{ml}$ of lysozyme $\left(40 \mathrm{mg} / \mathrm{ml}\right.$ in $0.25 \mathrm{M}$ Tris, $\mathrm{pH} 8.0$ ) and $1.25 \mathrm{ml}$ of $\mathrm{Na}_{2}$ EDTA $(0.25 \mathrm{M}, \mathrm{pH} 8.0)$ were added to each tube. The contents were mixed by inversion and incubated at $37^{\circ} \mathrm{C}$ for $2 \mathrm{~h}$. Lysis was then accomplished by the addition of $12.5 \mathrm{ml}$ of $\mathrm{N}$ lauroylsarcosine $(2 \%$ in $0.05 \mathrm{M}$ Tris, $\mathrm{pH} 8.0-1.5 \mathrm{M} \mathrm{NaCl}$ ) which had been prewarmed to $37^{\circ} \mathrm{C}$. Some strains required additional $\mathrm{N}$-lauroylsarcosine for lysis (1-2 $\mathrm{ml}$ of a $20 \%$ solution in water). After an additional $15-30 \mathrm{~min}$ at $37^{\circ} \mathrm{C}$, the lysates were sheared by five passages through a $35-\mathrm{ml}$ glass syringe without a needle. They were then held on ice at $0^{\circ} \mathrm{C}$ until alkali treatment. The $\mathrm{pH}$ of each lysate was raised to $12.1-12.2$ with $\mathrm{NaOH}(4.0 \mathrm{~N})$ at room temperature, waiting $10-15 \mathrm{~s}$ after each addition of alkali to permit equilibration of the viscous lysate with stirring. A total of $2-4 \mathrm{ml}$ of $\mathrm{NaOH}$ was usually required. After waiting at least a minute with the $\mathrm{pH}$ at $12.1-12.2$, Tris $(2.0 \mathrm{M}, \mathrm{pH} 5.0)$ was added until the $\mathrm{pH}$ again reached 8.0 ; this usually required $25-35 \mathrm{ml}$. As soon as the $\mathrm{pH}$ had returned to 8.0 , $12.5 \mathrm{~g}$ of nitrocellulose (kindly provided by Hercules, Inc., Wilmington, Del., RS $0.5 \mathrm{~s}$ ) was added to the lysate and stirring was continued at $4^{\circ} \mathrm{C}$ for another $45 \mathrm{~min}$. (Before use, the nitrocellulose had been washed four times with a liter of $0.3 \mathrm{M} \mathrm{NaCl}-0.03 \mathrm{M} \mathrm{Na}$ citrate solution, and allowed to dry in the air without exposure to heat). After stirring, the nitrocellulose was allowed to sediment. The cloudy supernate was decanted and centrifuged at $2,500 \mathrm{~g}$ for $10 \mathrm{~min}$ at $4^{\circ} \mathrm{C}$ to remove additional nitrocellulose. The resulting supernate was carefully layered onto a $2.5-\mathrm{ml}$ cushion of TES containing $\mathrm{CsCl}(61.7 \% \mathrm{wt} / \mathrm{wt})$ and centrifuged for $14 \mathrm{~h}$ in a type 30 rotor at $14,000 \mathrm{rpm}(17,000 \mathrm{~g})$ with a Beckman model L ultracentrifuge (Beckman Instruments, Inc., Spinco Division, Palo Alto, Calif.) at $8^{\circ} \mathrm{C}$.
After centrifugation, all but the bottom $10 \mathrm{ml}$ was removed from each tube; the pellet was homogenized with a glass stirring rod and the suspension was filtered through glass wool to remove residual nitrocellulose. The refractive index of the filtrate was adjusted to 1.400 by the addition of $\sim 5.7 \mathrm{~g}$ of $\mathrm{CsCl}$. Before isopyonic ultracentrifugation, $0.2 \mathrm{ml}$ of Tris $(0.05 \mathrm{M}, \mathrm{pH} 8.0)$ containing ethidium bromide $(5 \mathrm{mg} / \mathrm{ml})$ was added to each tube. Gradients were centrifuged at 33,000 $\mathrm{rpm}(72,000 \mathrm{~g})$ for $40 \mathrm{~h}$ in a Beckman model L ultracentrifuge at $8^{\circ} \mathrm{C}$ with a type 40 rotor. After centrifugation, satellite bands were identified with the aid of a long wave ultra-violet lamp (Chromato-Vue Transilluminator, model C-62, Ultra-Violet Products, Inc., San Gabriel, Calif.) and removed with a fractioning device. Ethidium bromide was removed by two extractions with equal volumes of cesium chloride-saturated isopropanol. Cesium chloride was removed by dialysis against TES, allowing $1-2 \mathrm{~h}$ for the first change, and $4-6 \mathrm{~h}$ for the second, at $4^{\circ} \mathrm{C}$.

\section{Agarose gel electrophoresis of DNA}

The method of Meyers et al. (16) was used with several minor modifications. Crude lysates were treated (final concentration of $200 \mu \mathrm{g}$ pronase per $\mathrm{ml}$ ) for $30 \mathrm{~min}$ at $37^{\circ} \mathrm{C}$ rather than extracted with phenol. The $\mathrm{E}$ buffer of Sharp et al. (17) was used rather than a Tris-borate buffer, and 1.0\% agarose (Sigma Chemical Co.) was employed for the vertical slab gel. A short-wave ultraviolet light source (ChromatoVue Transilluminator, model C-61, Ultra-Violet Products, Inc.) was used to photograph gels after ethidium bromide staining.

\section{Electron microscopy of plasmid DNA}

Satellite bands removed from $\mathrm{CsCl}$-ethidium bromide gradients for study by electron microscopy were dialyzed against $0.05 \mathrm{M}$ Tris, $0.002 \mathrm{M} \mathrm{Na}_{2}$ EDTA, pH 8.5, to remove $\mathrm{CsCl}$ after extraction with isopropanol. Plasmid DNA obtained from the satellite band of Escherichia coli strain JC 411 containing the plasmid ColEl (wt, 4.2 megadaltons) (18) was incorporated in DNA preparations to provide an internal marker for measuring the size of the enterococcal plasmid. Grids coated with $3.5 \%$ parlodion were used to pick up DNA spread onto the aqueous $0.25 \mathrm{M}$ ammonium acetate hypophase (19). They were stained in $10 \mathrm{ml}$ of $90 \%$ ethanol ( $\mathrm{vol} / \mathrm{vol}$ ) containing uranyl acetate $(100 \mu \mathrm{l}$ of a $50 \mathrm{mM}$ solution in glass-distilled water) for $30 \mathrm{~s}$, and rinsed in $90 \%$ ethanol for another $30 \mathrm{~s}$ before being allowed to dry (20). Grids were shadowed with platinum-palladium by a JEOL vacuum shadower (JEOL Analytical Instruments, Cranford, N. J., model JEE-4C). They were examined and photographed with RCA 3G and Philips 200 electron microscopes (RCA Solid State, Somerville, N. J. and Philips Electronic Instruments, Inc., Mahwah, N. J.).

Measurements of plasmid size were obtained by tracing projected images of plasmids from electron photomicrographs with an electronic graphics calculator in the length mode (model 250-117, Numonics Corp., Lansdale, Pa.) and comparing the size (length) of the enterococcal plasmid with ColEl. Three measurements were made of each plasmid to obtain an average. Established statistical methods were used to calculate the standard deviation (21).

\section{Synergism experiments}

These were performed according to the protocol of Moellering et al. (9). Synergism was defined as a 100-fold (2 
$\log _{10}$ ) increase in killing at $24 \mathrm{~h}$ by both drugs as compared with penicillin alone (4). Aminoglycosides alone, when used at clinically achievable concentrations, do not interfere with the growth of enterococci.

\section{Novobiocin treatment}

We used the method of McHugh and Swartz (22). Novobiocin solutions were prepared fresh on the day of use in Pen-Assay Broth, sterilized by passage through a $0.45-\mu \mathrm{m}$ Millipore filter (Millipore Corp.), and diluted with sterile Pen-Assay Broth to produce the desired range of novobiocin concentrations. 25 colonies were selected from BHI agar subcultures obtained from two tubes containing $10^{5}$ colony forming units per $\mathrm{ml}$ and replica plated from a master plate (BHI agar without antibiotics) by the velvet technique (23) onto plates containing streptomycin $(2,000 \mu \mathrm{g} / \mathrm{ml})$ and kanamycin $(2,000 \mu \mathrm{g} / \mathrm{ml})$, as well as plain BHI. Colonies which did not grow on either antibiotic containing medium were inoculated into liquid BHI and grown overnight for reexamination by plating with a modified Steers et al. replicator (14). Single colonies were again isolated on BHI agar and retested to confirm their antibiotic resistance pattern before they were examined by cesium chloride-ethidium bromide ultracentrifugation or used in antibiotic synergism studies.

\section{RESULTS}

\section{Mating experiments}

Three resistant clinical isolates were studied and found to transfer high-level streptomycin and kanamycin resistance to the sensitive recipient, JH2-7 (Table I).

\section{Mating experiment controls for transformation and transduction}

Transformation. Treatment of donor and recipient cultures and the mating mixture with DNase I and $\mathrm{MgSO}_{4}$ did not reduce the frequency of transfer observed.

$\left[{ }^{3} \mathrm{H}\right] D N A$ assay of DNase I activity. After demonstrating the activity of DNase I in distilled water and

\section{TABLE I}

Transfer of High-Level Aminoglycoside Resistance with Clinical Isolates of S. faecalis*

\begin{tabular}{lc}
\hline Donor strain & Frequency of transfer \\
\hline 8436 & $6.9 \times 10^{-7}$ \\
EBC-15 & $1.0 \times 10^{-3}$ \\
EBC-22 & $3.0 \times 10^{-2}$
\end{tabular}

* Each experiment utilized the recipient strain of Jacob and Hobbs, JH2-7, (12), and measured the transfer of high-level streptomycin and kanamycin resistance $(2,000 \mu \mathrm{g} / \mathrm{ml})$.

$\ddagger$ The frequency of transfer is the number of transconjugants per milliliter divided by the number of resistant donor organisms per milliliter. in BHI broth made with distilled water, the assay was repeated in $\mathrm{BHI}$ broth during the mating of strains EBC-22 (pDR 1) and JH2-7. In each instance (water, BHI broth, and mating in BHI), tubes without DNase I yielded 6-7,000 cpm. Tubes with DNase I were actually slightly lower than background $(200 \mathrm{cpm})$. It made no difference whether $\left[{ }^{3} \mathrm{H}\right] \mathrm{DNA}$ was added at zero time, or after 1 or $3 \mathrm{~h}$ of the 4 -h incubation. Thus DNase I, at the concentration employed, retained its activity throughout the 4-h incubation. The frequency of transfer observed was actually slightly greater (not significantly) in the presence of DNase I, than in controls. Therefore, it seems unlikely that transformation could account for the observed transfer of aminoglycoside resistance.

Transduction. Evidence of resistance transfer was not detected (i.e., frequency of transfer $\leqslant 10^{-9}$ ) when filtrates of resistant isolates were mixed with the recipient strain. Similarly, no plaques were detected on a soft agar overlay containing the recipient strain, JH2-7. Thus, transduction also did not seem responsible for the transfer of resistance.

\section{Cesium chloride-ethidium bromide ultracentrifugations}

Satellite bands were identified in $\mathrm{CsCl}$-ethidium bromide gradients prepared from five different resistant clinical isolates, but not in gradients prepared from the sensitive recipient, JH2-7. However, after a resistant clinical isolate EBC-22 (pDR 1), that contained a single plasmid ( $\mathrm{pDR} 1$ ), was mated with JH2-7, the transconjugant strain JH2-7 (pDR 1) acquired a satellite band (Fig. 1).

Eight transconjugant strains derived from isolate EBC-22 (pDR 1) have been examined and found to contain an extrachromosomal (satellite) band on cesium chloride-ethidium bromide ultracentrifugation, as have five transconjugants from isolate EBC-15 and two from isolate 8436. Other strains examined include two clinical isolates without high-level aminoglycoside resistance which did not reveal satellite bands on cesium chloride-ethidium bromide ultracentrifugation, and two clinical isolates with high-level aminoglycoside resistance (not studied for ability to transfer) which did reveal satellite bands on ultracentrifugation. Similar results were obtained with both the methods of Jacob and Hobbs (12) and Palchaudhuri and Chakrabarty (15). Precipitation of chromosomal DNA in the presence of $1.0 \mathrm{M} \mathrm{NaCl}$ after lysis with $\mathrm{N}$ lauroylsarcosine or Triton $\mathrm{X}-100 / \mathrm{Na}$ deoxycholate (Rohm \& Haas Co., Philadelphia, Pa.) failed to reveal a satellite band in either the resistant clinical isolates or the transconjugant strain. We detected a satellite band in cells lysed with $\mathrm{N}$-lauroylsarcosine only if they were treated with RNase before lysis (12) or 


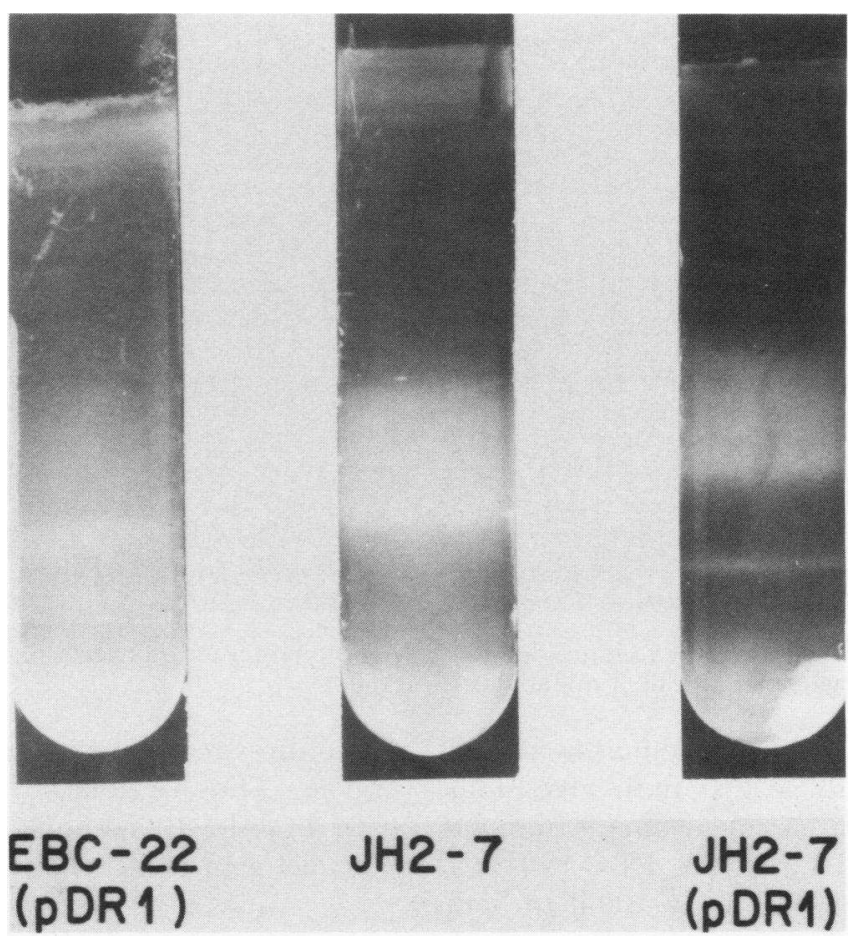

FIGURE 1 Photograph of three cesium chloride-ethidium bromide gradients after ultracentrifugation. The DNA on these gradients was prepared by the alkali-nitrocellulose technique (15) from a resistant clinical isolate (EBC-22 [pDR 1]), the sensitive recipient (JH2-7), and the transconjugant (JH2-7 [pDR 1]).

alkali after lysis (15). RNase-lysozyme pretreatment permitted the isolation of plasmid pDR 1 from strain EBC-22 with or without heat inactivation of the RNase.

\section{Agarose gel electrophoresis of plasmid DNA}

Plasmid DNA obtained by cesium chloride-ethidium bromide ultracentrifugation was subjected to agarose gel electrophoresis after extraction of ethidium bromide and removal of $\mathrm{CsCl}$ by dialysis as described above. A common plasmid band was observed in five resistant clinical isolates and in the transconjugant strain JH2-7 (pDR 1), as well as transconjugants derived from strain EBC-15; its weight was estimated to be $\mathbf{4 5}$ megadaltons by calibration with plasmids of known size (16). No satellite band was available to test from the sensitive recipient, JH2-7. Multiple attempts to demonstrate extrachromosomal DNA by the technique of Meyers et al. (16) (modified as described above) with sodium dodecyl sulfate lysis revealed smaller plasmids (3-8 megadaltons) in several strains resistant to erythromycin, but failed to demonstrate the 45 megadalton plasmid in either resistant clinical isolates or the transconjugant strains. That this was not related to technical problems with the agarose gel electrophoresis was shown by control experiments in which we were able to demonstrate plasmids varying from 25 through 100 megadaltons from crude lysates of E. coli.

\section{Electron microscopy}

Although circular molecules of similar size were observed in plasmid DNA preparations from strain EBC-22 (pDR 1), detailed measurements were made only on electron photomicrographs of the satellite band obtained from the transconjugant strain (JH2-7 [pDR 1]) (Fig. 2). 11 circular molecules were measured. Based upon the relative length of the ColEl molecule (4.2 megadaltons) (18), the size of the enterococcal plasmid was calculated to be 45 megadaltons ( 44.8 \pm 2.8 , mean $\pm \mathrm{SD}(21)$ ).

\section{Synergism studies}

The clinical isolate, EBC-22 (pDR 1), with highlevel resistance to streptomycin and kanamycin, was also resistant to penicillin-streptomycin and penicillinkanamycin synergism (Fig. 3). The recipient strain, JH2-7, which was sensitive to high-level streptomycin and kanamycin, was also sensitive to penicillin-aminoglycoside synergism (Fig. 4). However, the transconjugant strain JH2-7 (pDR 1), which acquired highlevel resistance to streptomycin and kanamycin after 


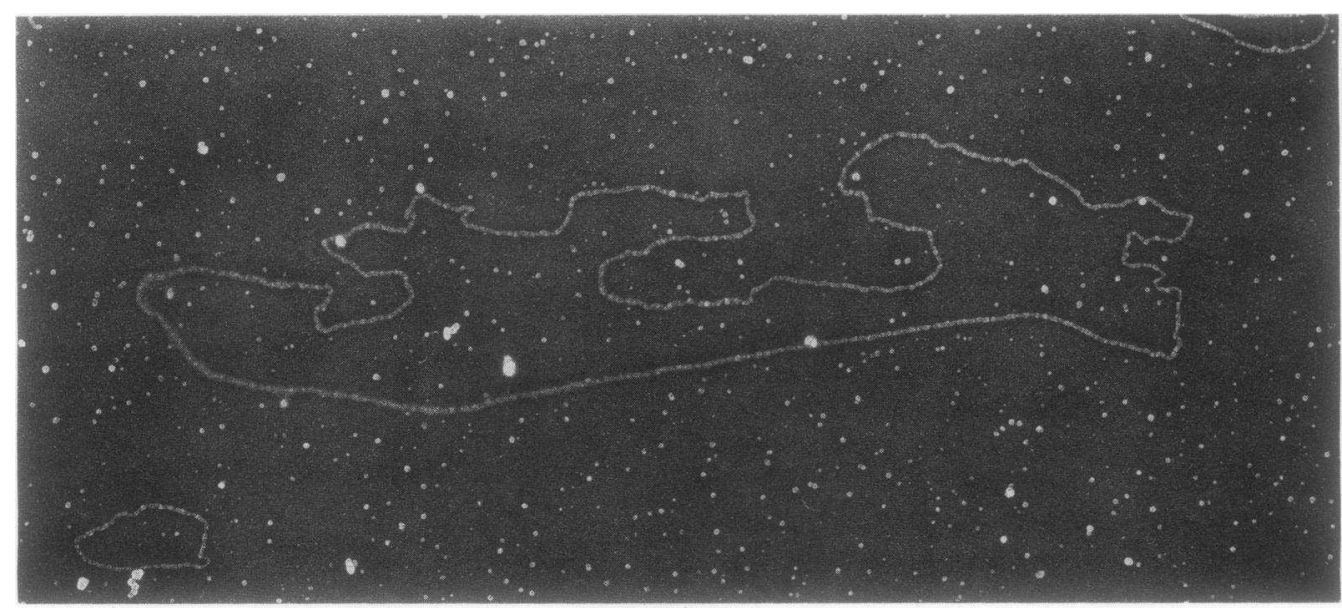

FIGURE 2 Electron photomicrograph demonstrating the larger enterococcal plasmid (pDR 1) in the center and two smaller ColEl molecules $(\times 13,600)$.

mating, also acquired resistance to penicillin-aminoglycoside synergism with those two aminoglycosides (Fig. 5). Nine additional transconjugant strains from the EBC-22/JH2-7 cross, and 10 from the EBC-15/JH2-7 cross have been studied and found resistant to both

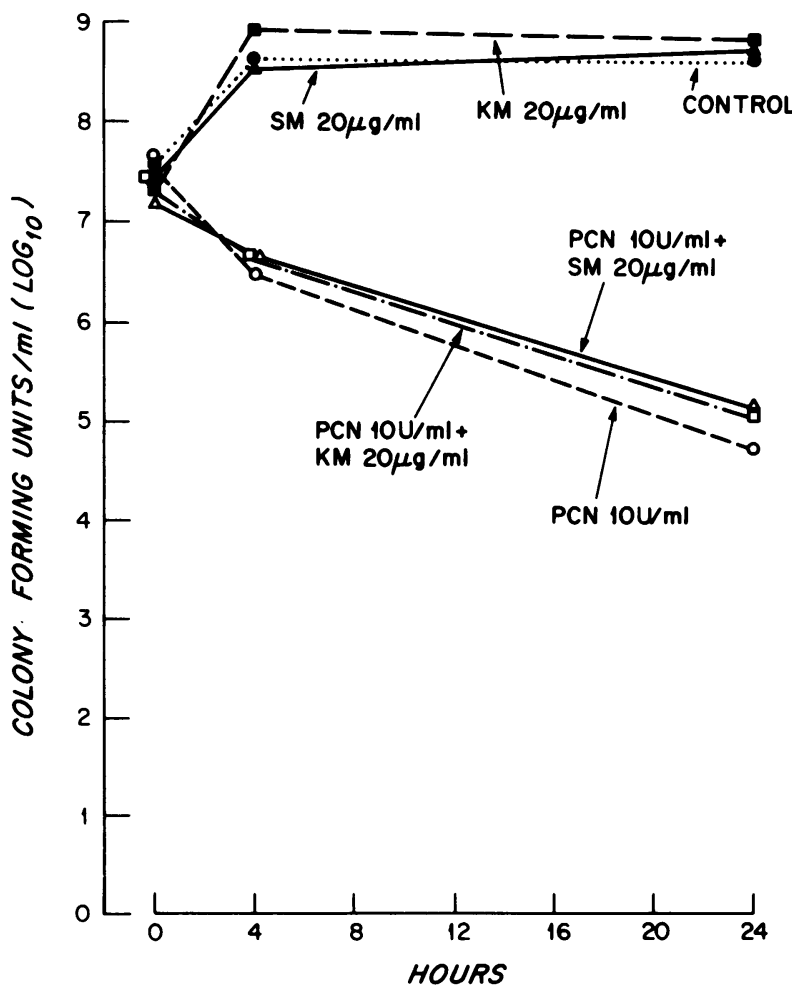

FIgURE 3 Effect of streptomycin and kanamycin alone and in combination with penicillin against clinical isolate EBC-22 (pDR 1) which was resistant to penicillin-streptomycin and penicillin-kanamycin antibiotic synergism. $\mathrm{PCN}=$ penicillin, $\mathrm{SM}=$ streptomycin, $\mathbf{K M}=$ kanamycin penicillin-streptomycin and penicillin-kanamycin synergism. Thus, a total of 20 transconjugant strains with high-level aminoglycoside resistance have all demonstrated resistance to antibiotic synergism.

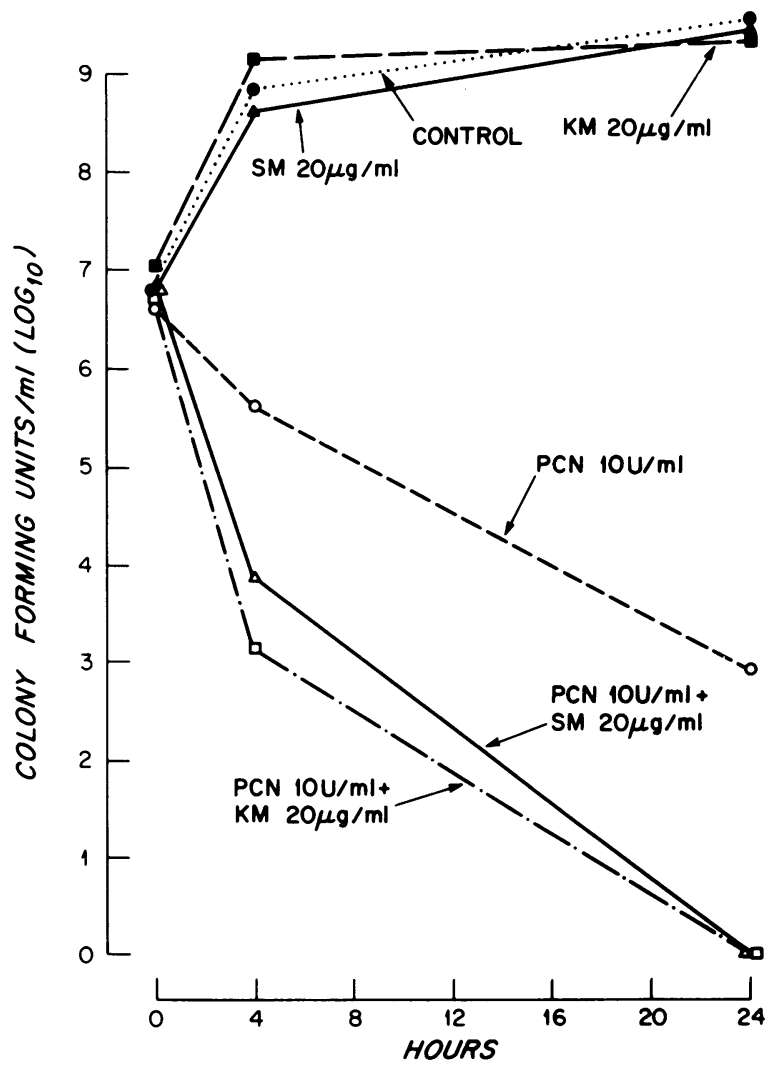

FIGURE 4 Effect of streptomycin and kanamycin alone and in combination with penicillin against the recipient strain JH2-7 which was susceptible to penicillin-streptomycin and penicillin-kanamycin synergism. $\mathrm{PCN}=$ penicillin, $\mathrm{SM}=$ streptomycin, $\mathbf{K M}=$ kanamycin. 


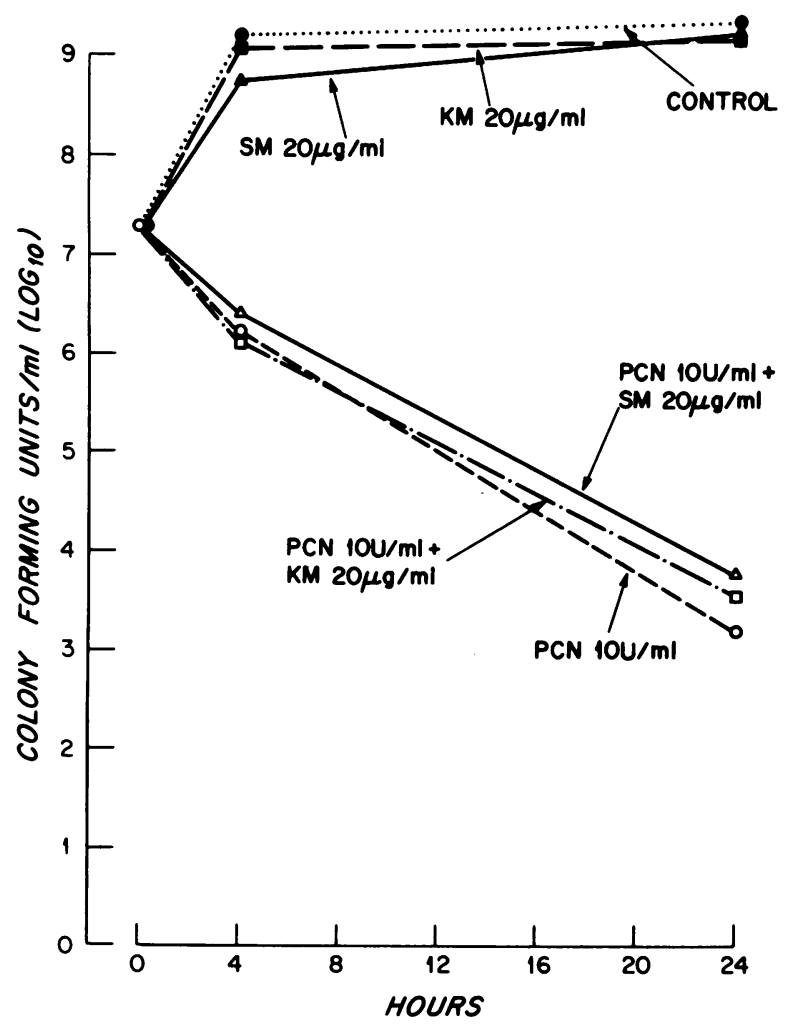

FIGURE 5 Effect of streptomycin and kanamycin alone and in combination with penicillin against the transconjugant derived from mating strain EBC-22 (pDR 1), with strain JH2-7. The transconjugant, strain JH2-7 (pDR 1), acquired resistance to penicillin-streptomycin and penicillin-kanamycin synergism. $\mathrm{PCN}=$ penicillin, $\mathrm{SM}=$ streptomycin, $\mathrm{KM}$ $=$ kanamycin.

\section{Novobiocin treatment}

After $18 \mathrm{~h}$ of exposure to novobiocin (1-2 $\mu \mathrm{g} / \mathrm{ml})$, cultures of EBC-22 (pDR 1) remained at their original concentration of $10^{5}$ colony forming units per ml. However, $32 \%$ (16/50) of colonies examined from BHI agar subcultures of these tubes after novobiocin treatment were no longer resistant to high-level streptomycin and kanamycin. No loss of resistance occurred among 25 colonies examined from tubes that did not contain novobiocin.

10 of the novobiocin treated strains that had lost their high-level resistance to streptomycin and kanamycin were studied by cesium chloride-ethidium bromide ultracentrifugation. In nine instances, the plasmid band was no longer present: in the other, it was reduced in intensity when observed by ultraviolet light, and it decreased in size when studied by agarose gel electrophoresis. Synergism studies revealed that loss of high-level aminoglycoside resistance was associated with loss of resistance to penicillin-aminoglycoside synergism in the two strains studied (one with plasmid loss and the other with reduction in plasmid size (Fig. 6).

\section{DISCUSSION}

Our results demonstrate for the first time, that resistance to antibiotic synergism among clinical isolates of enterococci is transferable. In addition, we have observed that resistance to penicillin-aminoglycoside synergism is transferred and(or) lost together with high-level aminoglycoside resistance in the laboratory. These findings strengthen the previously established association among clinical isolates of enterococci between high-level aminoglycoside resistance and resistance to antibiotic synergism with penicillin and that aminoglycoside $(8,11)$. Likewise, our results are consistent with the report of Jacob and Hobbs that highlevel resistance to streptomycin and kanamycin was transferable in a clinical enterococcal isolate they obtained from the Hammersmith Hospital in London (12). However, they did not examine either the original isolate or transconjugant for their response to antibiotic synergism.

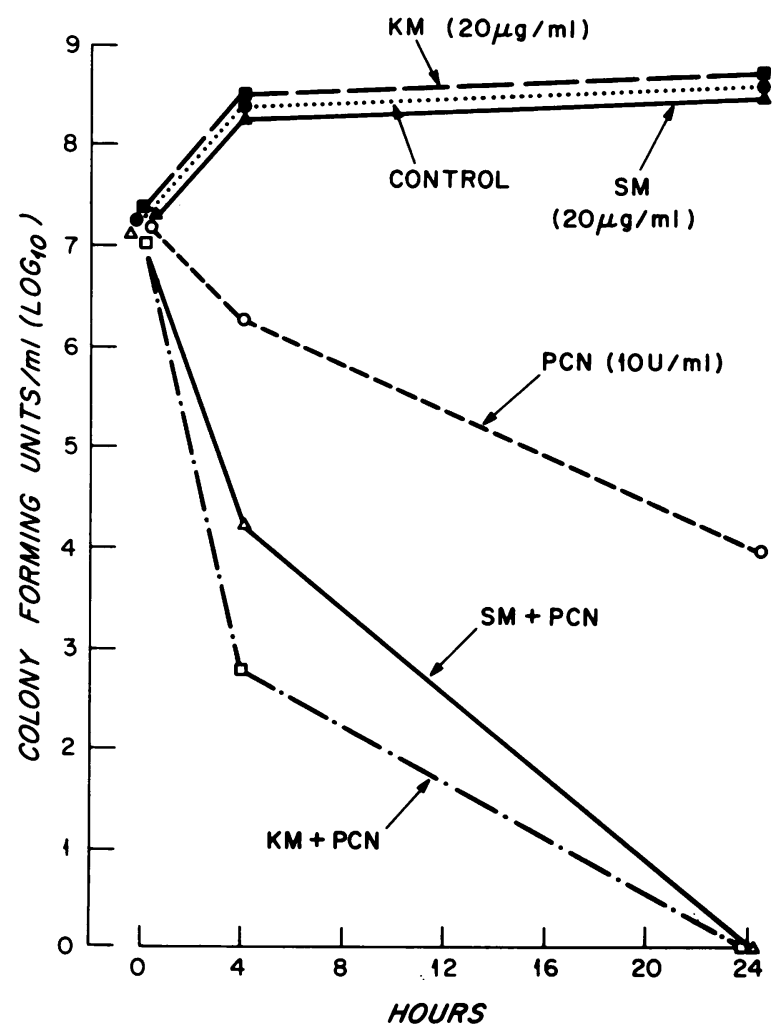

FIGURE 6 Effect of streptomycin and kanamycin alone and in combination with penicillin against the clinical isolate (EBC-22 [pDR 1]) which was no longer resistant to penicillin-streptomycin or penicillin-kanamycin synergism after novobiocin treatment. $\mathrm{PCN}=$ penicillin; $\mathrm{SM}=$ streptomycin, $\mathbf{K M}=$ kanamycin. 
Because DNase I treatment did not reduce the frequency of transfer, and cell-free filtrates failed to transfer the resistance markers, the most likely mechanism of the transfer we have observed is conjugation, rather than transformation or transduction. These findings are also similar to the earlier work of Jacob and Hobbs (12).

Why the frequency of transfer observed with these strains varies over such a wide range $\left(3 \times 10^{-2}\right.$ to 6.9 $\left.\times 10^{-7}\right)$ is not clear. Although transfer frequencies approaching $100 \%$ have been reported among gramnegative bacteria (24), the upper end of the range found here $\left(3 \times 10^{-2}\right)$ may be the highest described to date among gram-positive organisms. Because the recipient strain, JH2-7, which is sensitive to antibiotic synergism, acquired resistance to penicillin-streptomycin and penicillin-kanamycin synergism after acquisition of a plasmid from a resistant clinical isolate, these results suggest that gene(s) involved in resistance to penicillin-aminoglycoside synergism are present on that plasmid, and that they may be the same gene(s) responsible for high-level resistance to streptómýcin and kanamycin.

Several lines of evidence from physical studies, including cesium chloride-ethidium bromide ultracentrifugation, agarose gel electrophoresis, and electron microscopy, corroborate the association of the 45megadalton plasmid with both high-level resistance to streptomycin and kanamycin, and resistance to penicillin-streptomycin and penicillin-kanamycin synergism. Although smaller plasmids (3-8 megadaltons) were present in several erythromycin-resistant clinical isolates, the 45-megadalton plasmid was the only one consistently present in strains with high-level resistance to streptomycin and kanamycin. In addition, acquisition of the 45-megadalton plasmid (without the smaller plasmid) by the sensitive recipient strain coincided with acquisition of both high-level aminoglycoside resistance and resistance to penicillinaminoglycoside synergism, whereas loss of the plasmid or a reduction in its size (after novobiocin treatment) coincided with loss of both these traits. Although examination of several other clinical enterococcal isolates with high-level aminoglycoside resistance by agarose gel electrophoresis (after cesium chlorideethidium bromide ultra-centrifugation) revealed a plasmid of similar size, we do not have enough information to generalize about plasmids in $S$. faecalis clinical isolates with high-level aminoglycoside resistance.

It is not yet clear why isolation of this plasmid appears to require either RNase treatment before lysis or alkali treatment after lysis. Although we have no direct evidence for their presence, one possible explanation would be RNA linkages between plasmid and chromosomal DNA, as have been suggested in
E. coli (25). Another potential explanation would be DNA-DNA interactions between the chromosome and plasmid. Although alkali treatment denatures both DNA and RNA (26), RNase treatment was effective with or without heat inactivation. Therefore, these results are most consistent with RNA linkages between the plasmid and chromosome.

Novobiocin is known to interfere in vitro with the activity of DNA gyrase from E. coli (27), and novobiocin treatment has been shown to eliminate plasmids from a variety of bacterial hosts (22). Therefore, 10 single-colony isolates which had lost high-level aminoglycoside resistance after novobiocin treatment of a resistant clinical strain were examined by cesium chloride-ethidium bromide ultracentrifugation. Although a plasmid band was still present in 1 of the 10 isolates, the plasmid was reduced in size when examined by agarose gel electrophoresis. These results suggest that, on occasion, novobiocin treatment may induce or select for deletion of plasmid genes. Both patterns observed after novobiocin treatment (i.e., loss of the entire plasmid or a significant reduction in its size) are compatible with the loss of genes related to aminoglycoside resistance and resistance to antibiotic synergism.

The simultaneous loss of both high-level resistance and resistance to synergism suggests that the genes controlling these traits are on the same plasmid. It does not establish whether they are identical or merely linked.

Our present hypothesis is that the gene(s) responsible for high-level resistance to aminoglycosides are also responsible for resistance to antibiotic synergism with penicillin and that aminoglycoside in enterococci. These studies clearly relate high-level aminoglycoside resistance and resistance to antibiotic synergism among some clinical isolates of enterococci to the presence of a transferable 45 megadalton plasmid. We suggest that the prevalence of highlevel aminoglycoside resistance and resistance to antibiotic synergism currently observed in many other centers, may also be plasmid mediated.

\section{ACKNOWLEDGMENTS}

We gratefully acknowledge the encouragement and advice of George Jacoby, Alan E. Jacob, Romaine R. Bruns, and Phillip A. Sharp, and the assistance of Gail L. McHugh, Mary Ann Waldron, and Lawrence J. Kunz. The secretarial assistance of Mrs. Florence Larson is also gratefully acknowledged.

The research for this paper was supported by National Institutes of Health grants 5-1 AI 00215-15 and $1132 \mathrm{AI}$ 07061-01.

\section{REFERENCES}

1. Moellering, R. C., Jr., B. K. Watson, and L. J. Kunz. 1974. Endocarditis due to group D streptococci: Comparison of 
disease caused by Streptococcus bovis with that produced by enterococci. Am. J. Med. 57: 239-250.

2. Hunter, T. H. 1947. Use of streptomycin in treatment of bacterial endocarditis. Am. J. Med. 2: 436-442.

3. Jawetz, E., J. B. Gunnison, and V. R. Colman. 1950. The combined action of penicillin with streptomycin or chloromycetin on enterococci in vitro. Science (Wash. D. C.). 111: $254-256$.

4. Moellering, R. C., Jr., C. Wennersten, and A. N. Weinberg. 1971. Studies on antibiotic synergism against enterococci. I Bacteriologic studies. J. Lab. Clin. Med. 77: 821-828.

5. Hook, E. W., III, R. B. Roberts, and M. A. Sande. 1975. Antimicrobial therapy of experimental enterococcal endocarditis. Antimicrob. Agents Chemother. 8: 564-570.

6. Moellering, R. C., Jr., and A. N. Weinberg. 1971. Studies on antibiotic synergism against enterococci. II. Effect of various antibiotics on the uptake of ${ }^{14} \mathrm{C}$-labelled streptomycin by enterococci. J. Clin. Invest. 50: 25802584.

7. Iannini, P. B., J. Ehret, and T. C. Eickhoff. 1976. Effects of ampicillin-amikacin and ampicillin-rifampin on enterococci. Antimicrob. Agents Chemother. 9: 448-451.

8. Standiford, H. D., H. B. deMaine, and W. M. M. Kirby. 1970. Antibiotic synergism of enterococci. Arch. Intern. Med. 126: 255-259.

9. Moellering, R. C. Jr., C. Wennersten, T. Medrek, and A. N. Weinberg. 1971. Prevalence of high-level resistance to aminoglycosides in clinical isolates of enterococci. Antimicrob. Agents Chemother. 335-340.

10. Ruhen, R. W., and J. W. Darrell. 1973. Antibiotic synergism against group D streptococci in the treatment of endocarditis. Med. J. Aust. 2: 114-116.

11. Calderwood, S. A., C. Wennersten, R. C. Moellering Jr., L. J. Kunz, and D. J. Krogstad. 1977. Resistance to six aminoglycosidic aminocyclitol antibiotics among enterococci: Prevalence, evolution and relationship to synergism with penicillin. Antimicrob. Agents Chemother. 12: $401-405$.

12. Jacob, A. E., and S. J. Hobbs. 1974. Conjugal transfer of plasmid-borne multiple antibiotic resistance in Streptococcus faecalis var. zymogenes. J. Bacteriol. 117 : 360-372.

13. Facklam, R. R. 1972. Recognition of group D streptococcal species of human origin by biochemical and physiological tests. Appl. Microbiol. 23: 1131-1139.

14. Steers, E., E. L. Foltz, B. S. Graves, and J. Riden. 1959. An inocula replicating apparatus for routine testing of bacterial susceptibility to antibiotics. Antibiot. Chemother. (Basel). 9: 307-311.

15. Palchaudhuri, S., and A. Chakrabarty. 1976. Isolation of plasmid deoxyribonucleic acid from Pseudomonas putida. J. Bacteriol. 126: 410-416.

16. Meyers, J. A., D. Sanchez, L. P. Elwell, and S. Falkow. 1976. Simple agarose gel electrophoretic method for the identification and characterization of plasmid deoxyribonucleic acid. J. Bacteriol. 127: 1529-1537.

17. Sharp, P. A., B. Sugden, and J. Sambrook. 1973. Detection of two restriction endonuclease activities in Haemophilus parainfluenzae using analytical agarose-ethidium bromide electrophoresis. Biochemistry. 12: 3055-3063.

18. Bazaral, M., and D. R. Helinski. 1968. Circular DNA in forms of colicinogenic factors E1, E2 and E3 from E. coli. J. Mol. Biol. 36: 185-194.

19. Kleinschmidt, A. K. 1968. Monolayer techniques in electron microscopy of nucleic acid molecules. Methods Enzymol. 12B: $361-377$.

20. Davis, R. W., M. Simon, and N. Davidson. 1971. Electron microscope heteroduplex methods for mapping regions of base sequence homology in nucleic acids. Methods Enzymol. 21B: 413-428.

21. Schor, S. S. 1968. Fundamentals of biostatistics. G. P. Putnam, Inc. New York. 84-85.

22. McHugh, G. L., and M. N. Swartz. 1977. Elimination of plasmids from several bacterial species by novobiocin. Antimicrob. Agents Chemother. 12: 421-426.

23. Lederberg, J., and E. M. Lederberg. 1952. Replica plating and indirect selection of bacterial mutants. $J$. Bacteriol. 63: 399-406.

24. Korfhagen, T. R., J. C. Loper, and J. A. Ferrel. 1975. Pseudomonas aeruginosa $\mathrm{R}$ factors determining gentamicin plus carbenicillin resistance from patients with urinary tract colonizations. Antimicrob. Agents Chemother. 7: 64-68.

25. Kline, B. C., and J. R. Miller. 1975. Detection of nonintegrated plasmid deoxyribonucleic acid in the folded chromosome of Escherichia coli: Physicochemical approach to studying the unit of segregation. J. Bacteriol. 121: $165-172$.

26. White, A., P. Handler, and E. L. Smith. 1964. Nucleic acids and nucleoproteins. In Principles of Biochemistry. McGraw-Hill Book Co., Inc. New York, 3rd edition. $176-178$

27. Gellert, M., M. H. O'Dea, T. Itoh, and J. Tomizawa. 1976. Novobiocin and coumermycin inhibit DNA supercoiling catalyzed by DNA gyrase. Proc. Natl. Acad. Sci. U. S. A. 73: 4474-4478. 